\title{
Knowledge Management, Innovation and Big Data: Implications for Sustainability, Policy Making and Competitiveness
}

\author{
Patricia Ordóñez de Pablos ${ }^{1}$ and Miltiadis Lytras ${ }^{2,3, *(D)}$ \\ 1 Faculty of Economics and Business, The University of Oviedo, Avda del Cristo, \\ s/n. 33071 Oviedo-Asturias, Spain; patriop@uniovi.es \\ 2 Deree College-The American College of Greece, 15342 Aghia Paraskevi, Greece \\ 3 Effat College of Engineering, Effat University, P.O. Box 34689, Jeddah, Saudi Arabia \\ * Correspondence: mlytras@acg.edu; Tel.: +30-210-6009800
}

Received: 7 June 2018; Accepted: 16 June 2018; Published: 19 June 2018

check for updates

\begin{abstract}
This Special Issue of Sustainability devoted to the topic of "Knowledge Management, Innovation and Big Data: Implications for Sustainability, Policy Making and Competitiveness" attracted exponential attention of scholars, practitioners, and policy-makers from all over the world. Locating themselves at the expanding cross-section of the uses of sophisticated information and communication technology (ICT) and insights from social science and engineering, all papers included in this Special Issue contribute to the opening of new avenues of research in the field of innovation, knowledge management, and big data. By triggering a lively debate on diverse challenges that companies are exposed to today, this Special Issue offers an in-depth, informative, well-structured, comparative insight into the most salient developments shaping the corresponding fields of research and policymaking.
\end{abstract}

Keywords: big data; competitive advantage; disruptive innovation; human capital; innovation; knowledge management; sustainability

\section{Overview of the Special Issue}

Knowledge Management and Big Data is a new paradigm for the integration of Internet Technology in the human and machine contexts. Now, we are able to transform raw data that are massively produced by humans and machines into knowledge and wisdom capable of supporting disruptive innovation, smart decision making, innovative services, and new business models. This Special Issue explores the role of knowledge management strategies and tools to enhance the power of big data and help decision makers in today's competitive economy. The analysis of these key issues on the interrelations among knowledge management, big data, and information technology will provide new knowledge and perspectives towards a deeper understanding of their impact on companies, economies, and societies today.

The Special Issue opens with a paper by Shan et al. titled "Internal Social Network, Absorptive Capacity and Innovation: Evidence from New Ventures in China" [1]. The authors analyze "the impact of the internal social network on new venture's innovation by building a comprehensive structural equation modeling (SEM) that integrates three streams of research: internal social network, innovation, and absorptive capacity". In their research, they use a sample of 279 new ventures from China.

Wang et al., in their paper titled "Visualizing the Academic Discipline of Knowledge Management" [2], study "the research status of knowledge management (KM) and identify the characteristics of KM in the literature. We selected and studied in detail 7628 original research articles from the Web of Science from 1974 to 2017". 
In the paper titled "An Empirical Study on Visualizing the Intellectual Structure and Hotspots of Big Data Research from a Sustainable Perspective" [3], Hu et al. conducted a bibliometric study of big data literature from Web of Science (WoS) for the period 2002 to 2016, involving 4927 effective journal articles in 1729 journals contributed by 16,404 authors from 4137 institutions. The bibliometric outcomes show "the current annual publications distribution, journals distribution and co-citation network, institutions distribution and collaboration network, authors distribution, collaboration network and co-citation network, and research hotspots. The results can help researchers worldwide to understand the panorama of current big data research, to find the potential research gaps, and to focus on the future sustainable development directions".

López et al., in their paper titled "Semantic Modeling of Administrative Procedures from a Spanish Regional Public Administration" [4], explore how to improve public administration open data initiatives and help to develop their sustainability policies, such as improving decision-making procedures and administrative management sustainability. Using the methodology of a case study, the authors modelled public administrative processes and files in collaboration with a Regional Public Administration in Spain, the Principality of Asturias, which enabled access to its information systems.

Recognizing that little is known about the underlying relationship dynamics among the variables of transformational training programs, employee loyalty, and quality orientation of employees in the context of higher education institutions, Al Qudah et al. in their paper "Transformational Training Programs and Quality Orientation of Employees: Does Employees' Loyalty Matter?" [5] decide to explore the interplay of these variables. The outcomes of the research show "that both direct and indirect effects of transformational training programs on quality orientation of employees were significant. More specifically, the positive effects that transformational training programs have on quality orientation of employees are through employee loyalty. This finding significantly advances the existing body of knowledge and implies that transformational training programs enhance employees' loyalty which, in turn, escalates employees' orientations towards quality".

The paper titled "Ontology Design for Solving Computationally-Intensive Problems on Heterogeneous Architectures" [6] by Faheem et al. develops an ontology and shows "how we can use it to solve computationally-intensive problems from various domains. As a potential use for the idea, we present examples from the bioinformatics domain. Validation by using problems from the Elastic Optical Network domain has demonstrated the flexibility of the suggested ontology and its suitability for use with any other computationally-intensive problem domain".

Zhao et al., in their paper "Modeling and Quantifying User Acceptance of Personalized Business Modes Based on TAM, Trust and Attitude" [7], study the main factors influencing user acceptance of personalized business modes. The authors present a "research model that enhances the TAM (Technology Acceptance Model) model with trust and attitude to depict the influence from several variables to user acceptance of personalized business modes. Further, we use the structural equation method to conduct an empirical analysis on questionnaire data from the Internet. The results in terms of many kinds of data analysis show that trust and the TAM factors (perceived usefulness and perceived ease of use) have significant influence on user acceptance of personalized business modes".

In the paper titled "Existing Knowledge Assets and Disruptive Innovation: The Role of Knowledge Embeddedness and Specificity" [8], Lin et al. study the impact of "knowledge assets on disruptive innovation by analyzing the role of knowledge embeddedness and specificity. They conducted a hierarchical regression analysis by using survey data from 173 Chinese industrial firms to test the direct and indirect effects of knowledge embeddedness and specificity on disruptive innovation, which can be divided into outward-oriented and internal-oriented disruptive innovation. The results indicated that knowledge embeddedness not only played a positive role in knowledge specificity, but also had a positive effect on outward-oriented disruptive innovation".

In the paper "Business Intelligence Issues for Sustainability Projects" [9], Muntean argues that business intelligence is a term that encompasses strategies, technologies, and information systems used by companies and organizations "to extract from large and various data, according to the value 
chain, relevant knowledge to support a wide range of operational, tactical, and strategic business decisions. Sustainability, as an integrated part of the corporate business, implies the integration of the new approach at all levels: business model, performance management system, business intelligence project, and data model. Both business intelligence issues presented in this paper represent the contribution of the author in modeling data for supporting further BI approaches in corporate sustainability initiatives".

Liu et al., in the paper titled "Exploring the Technological Collaboration Characteristics of the Global Integrated Circuit Manufacturing Industry" [10], study the international technological collaboration characteristics of the integrated circuitry manufacturing industry based on patent analysis. The authors analyze "four aspects, which include collaboration patterns, collaboration networks, collaboration institutions, and collaboration impacts, by utilizing patent association analysis and social network analysis. The findings include the following: first, in regard to international technological collaboration, the USA has the highest level, while Germany has great potential for future development; second, Asia and Europe have already formed clusters, respectively, in the cooperative network; last, but not least, research institutions, colleges, and universities should also actively participate in international collaboration".

Hu et al., in their paper titled "A Hierarchical Feature Extraction Model for Multi-Label Mechanical Patent Classification" [11], developed "a hierarchical feature extraction model (HFEM) for multi-label mechanical patent classification, which is able to capture both local features of phrases as well as global and temporal semantics. First, a n-gram feature extractor based on convolutional neural networks (CNNs) is designed to extract salient local lexical-level features. Next, a long dependency feature extraction model based on the bidirectional long-short-term memory (BiLSTM) neural network model is proposed to capture sequential correlations from higher-level sequence representations. Then the HFEM algorithm and its hierarchical feature extraction architecture are detailed. We establish the training, validation and test datasets, containing 72,532, 18,133, and 2679 mechanical patent documents".

In the paper "Data Governance Taxonomy: Cloud versus Non-Cloud" [12], Al-Ruithe et al. admit that the only way to solve data problems is the implementation of effective data governance. The authors propose that "a taxonomy approach to define the different attributes of data governance is expected to make a valuable contribution to knowledge, helping researchers and decision makers to understand the most important factors that need to be considered when implementing a data governance strategy for cloud computing services. In addition to the proposed taxonomy, the paper clarifies the concepts of data governance in contracts with other governance domains".

Yu et al., in the paper "Knowledge Creation Process and Sustainable Competitive Advantage: the Role of Technological Innovation Capabilities" [13], study "the relationship between the knowledge creation process and technological innovation capabilities, and analyzes their effect on a firm's sustainable competitive advantage using a knowledge-based view theoretical framework. We conduct structural equation modeling analyses using survey data from 315 Chinese industrial firms to test the direct and indirect effects of the knowledge creation process on sustainable competitive advantage. Technological innovation capabilities-operationalized to reflect the dimensions of process innovation capability and product innovation capability—are used as the mediating variable for explaining the relationship between the knowledge creation process and sustainable competitive advantage. The results indicate that the knowledge creation process does not have a significant direct effect on sustainable competitive advantage".

$\mathrm{Wu}$ at al., in their paper titled "Top Management Teams' Characteristics and Strategic Decision-Making: A Mediation of Risk Perceptions and Mental Models" [14], propose that "strategic decision-making is a key factor of sustainability and development in enterprises. Moreover, the top management team (TMT) of an enterprise constitutes the base for decision-making. This study employed structural equation modeling to analyze questionnaires regarding TMTs' characteristics and strategic decision-making, and tested the mediating effects of risk perceptions and mental models and 
the moderating effects of psychological ownership. We investigated 289 valid questionnaires on TMTs completed by representatives from enterprises in China and found risk perceptions and mental models that serve as a mediating factor and are affected by the TMTs' characteristics and decision-making".

Roh et al. know the importance of text mining in patent analysis but also recognize its limitations. In their paper titled "Developing a Methodology of Structuring and Layering Technological Information in Patent Documents through Natural Language Processing" [15], the authors "structure meaningful keyword sets related to technological information from patent documents; then we layer the keywords, depending on the level of information. This research involves two steps. First, the characteristics of technological information are analyzed by reviewing the patent law and investigating the description of patent documents. Second, the technological information is structured by considering the information types, and the keywords in each type are layered through natural language processing. Consequently, the structured and layered keyword set does not omit useful keywords and the analyzer can easily understand the meaning of each keyword".

Can and Alatas, in the manuscript titled "Big Social Network Data and Sustainable Economic Development" [16], discuss that new information technologies contributed significantly to the rapid and effective growth of social networks. They propose that "the immediate or unpredictable effects of a wide array of economic activities on large masses and the reactions to them can be measured by using social media platforms and big data methods. Thus, it would be extremely beneficial to analyze the harmful environmental and social impacts that are caused by unsustainable business applications".

In the paper titled "Crowdsourcing Analysis of Twitter Data on Climate Change: Paid Workers vs. Volunteers" [17], Kirilenko et al. address the importance of web-based crowdsourcing for environmental data processing. The authors developed a study that compares "volunteer and paid processing of social media data originating from climate change discussions on Twitter. The same sample of Twitter messages discussing climate change was offered for processing to the volunteer workers through the Climate Tweet project, and to the paid workers through the Amazon MTurk platform. We found that paid crowdsourcing required the employment of a high redundancy data processing design to obtain quality that was comparable with volunteered processing. Among the methods applied to improve data processing accuracy, limiting the geographical locations of the paid workers appeared the most productive".

Zheng et al., in their paper titled "Impacts of Leadership on Project-Based Organizational Innovation Performance: The Mediator of Knowledge Sharing and Moderator of Social Capital" [18], explore the importance of innovation in the sustainable development of construction projects. In their paper, they study "various effects of different types of leadership on innovation performance in a construction project-based organization. Therefore, a theoretical model was constructed to explore the mediation mechanism and boundary condition of different types of leadership to improve innovation. The theoretical model was validated with empirical data covering project managers and engineers from the project-based organization in China via regression analysis and path analysis. The results show that transformational leadership and transactional leadership have some positively significant effects on knowledge sharing and innovation performance. Meanwhile, knowledge sharing partially mediates the relationship between transformational leadership and/or transactional leadership and innovation performance. Additionally, by considering different levels of social capital, transformational leadership is likely to have a strong positive impact on innovation performance through knowledge sharing".

García-Alcaraz et al., in the paper "Role of Human Knowledge and Communication on Operational Benefits Gained from Six Sigma" [19], focus on the implementation of a production philosophy called Six Sigma (SS). The paper proposes a "structural equation model integrating those aspects as latent variables and relating them with ten hypotheses. Data for hypothesis validation were gathered among 301 manufacturing companies, and assessed using partial least squares (PLS) to estimate direct, indirect, and total effects. As results, we found that access to reliable information, trusted analysis and knowledgeable management are crucial for SS implementation at the problem 
definition stage. Likewise, to execute and control SS projects, it is important to be trained in statistical techniques through clear didactic materials".

The paper "What Makes Firms Innovative? The Role of Social Capital in Corporate Innovation" [20] by Ahn and Kim developed a social capital explanation for the analysis of the relationship between human capital investment and the organizational innovation capability. The authors propose that "social capital plays a mediating role in the relationship between the level of individual knowledge of employees and organizations' innovation capabilities. The mediating mechanism is attributed to the role of social capital in knowledge exchange and combination that help enhance knowledge creation. They used a survey data of 319 manufacturing firms in Korea".

\section{Conclusions}

The excellent contributions from all over the world included in this Special Issue highlight diverse issues and topics that form the evolving field of knowledge management, big data, and innovation for the competitiveness of companies and economies. Thanks to this Special Issue, a substantial streamlining of the interrelation between big data and knowledge as triggers of innovation has been promoted. To capitalize on that work today, the imperative is to move to the next stage of the debate and explore more complex interrelations between these topics.

The overall contribution of this collection is the promotion of an integrative approach to the newly emerging, challenging research area of Big Data, Knowledge Management, and Innovation. What is evident from the relevant discussion is the promotion of four key aspects of novelty:

1. The fast developments in Artificial Intelligence and Machine Learning approaches.

2. The diffusion of numerous data and text mining techniques including sentiment analysis and social engineering.

3. The critical contribution of soft skills, and knowledge management process models to the efficiency of data-driven tasks and procedures.

4. The capacity of Big Data to support a multidisciplinary scientific intervention to real world social problems.

The new era of Big Data, Knowledge Management, and Innovation integration will be policy driven at a higher level of abstraction, where socially-inclusive economic growth and sustainability will be considered as top priorities. The multidisciplinary character of the phenomenon will be based on a critical and radical diffusion of Smart Machines and Artificial Intelligence [20-26] with a new Data-Knowledge-Wisdom ecosystem [See: Figure 1]; where knowledge artifacts and human and social entities will interact through new business models and applications powered by numerous new technologies such as augmented virtual reality, internet of things, sensors and 5G, cloud computing, anticipatory computing, and so on.

As a continuation of this Special Issue, we are planning a new Special Issue on Artificial Intelligence and Smart Machines for Sustainable Innovation Models. We would be happy to receiving the Sustainability community comments and feedback on the published research of this special issue. 


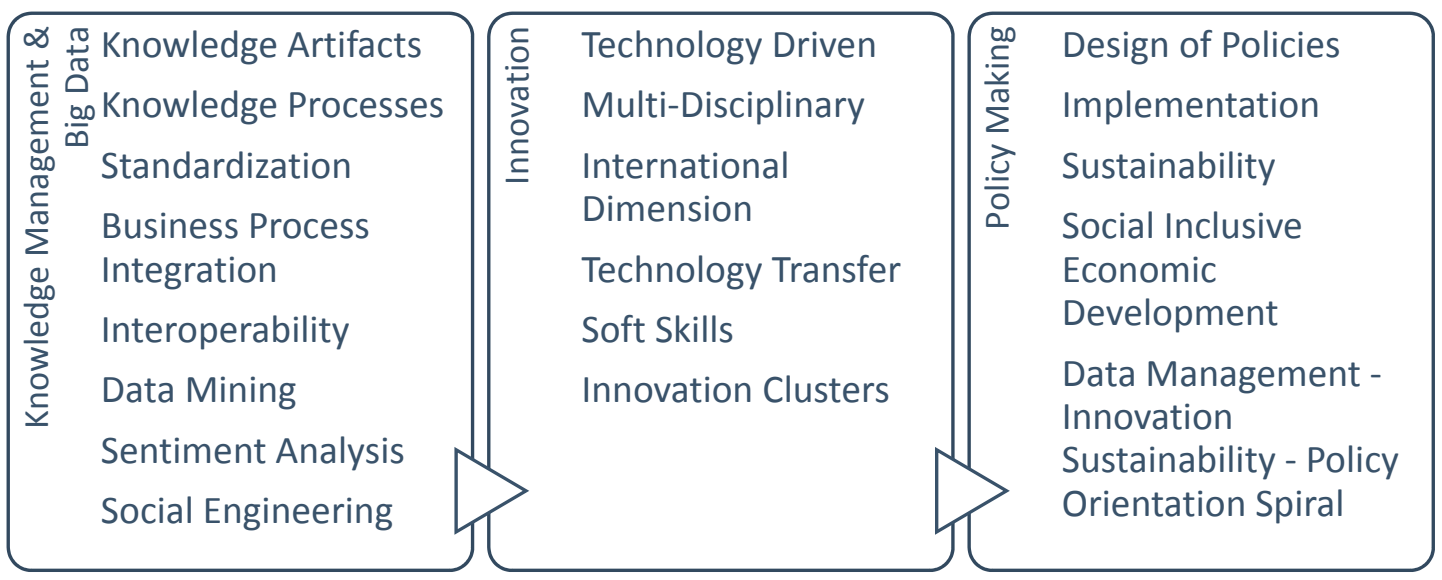

Figure 1. The Integrative KM, Innovation, Policy Making Research Landscape (source: The authors).

Conflicts of Interest: The authors declare no conflict of interest.

\section{References}

1. Shan, W.; Zhang, C.; Wang, J. Internal Social Network, Absorptive Capacity and Innovation: Evidence from New Ventures in China. Sustainability 2018, 10, 1094. [CrossRef]

2. Wang, P.; Zhu, F.; Song, H.; Hou, J.; Zhang, J. Visualizing the Academic Discipline of Knowledge Management. Sustainability 2018, 10, 682. [CrossRef]

3. Hu, F.; Liu, W.; Tsai, S.; Gao, J.; Bin, N.; Chen, Q. An Empirical Study on Visualizing the Intellectual Structure and Hotspots of Big Data Research from a Sustainable Perspective. Sustainability 2018, 10, 667. [CrossRef]

4. López, F.J.H.; Gayo, J.E.L.; de Pablos, P.O. Semantic Modeling of Administrative Procedures from a Spanish Regional Public Administration. Sustainability 2018, 10, 633. [CrossRef]

5. Al Qudah, N.F.; Yang, Y.; Anjum, M.A. Transformational Training Programs and Quality Orientation of Employees: Does Employees' Loyalty Matter? Sustainability 2018, 10, 465. [CrossRef]

6. Faheem, H.M.; König-Ries, B.; Aslam, M.A.; Aljohani, N.R.; Katib, I. Ontology Design for Solving Computationally-Intensive Problems on Heterogeneous Architectures. Sustainability 2018, 10, 441. [CrossRef]

7. Zhao, J.; Fang, S.; Jin, P. Modeling and Quantifying User Acceptance of Personalized Business Modes Based on TAM, Trust and Attitude. Sustainability 2018, 10, 356. [CrossRef]

8. Lin, C.; Li, B.; Wu, Y.J. Existing Knowledge Assets and Disruptive Innovation: The Role of Knowledge Embeddedness and Specificity. Sustainability 2018, 10, 342. [CrossRef]

9. Muntean, M. Business Intelligence Issues for Sustainability Projects. Sustainability 2018, 10, 335. [CrossRef]

10. Liu, Y.; Yan, Z.; Cheng, Y.; Ye, X. Exploring the Technological Collaboration Characteristics of the Global Integrated Circuit Manufacturing Industry. Sustainability 2018, 10, 196. [CrossRef]

11. Hu, J.; Li, S.; Hu, J.; Yang, G. A Hierarchical Feature Extraction Model for Multi-Label Mechanical Patent Classification. Sustainability 2018, 10, 219. [CrossRef]

12. Al-Ruithe, M.; Benkhelifa, E.; Hameed, K. Data Governance Taxonomy: Cloud versus Non-Cloud. Sustainability 2018, 10, 95. [CrossRef]

13. Yu, C.; Zhang, Z.; Lin, C.; Wu, Y.J. Knowledge Creation Process and Sustainable Competitive Advantage: The Role of Technological Innovation Capabilities. Sustainability 2017, 9, 2280. [CrossRef]

14. Wu, T.; Wu, Y.J.; Tsai, H.; Li, Y. Top Management Teams' Characteristics and Strategic Decision-Making: A Mediation of Risk Perceptions and Mental Models. Sustainability 2017, 9, 2265. [CrossRef]

15. Roh, T.; Jeong, Y.; Yoon, B. Developing a Methodology of Structuring and Layering Technological Information in Patent Documents through Natural Language Processing. Sustainability 2017, 9, 2117. [CrossRef]

16. Can, U.; Alatas, B. Big Social Network Data and Sustainable Economic Development. Sustainability 2017, 9, 2027. [CrossRef]

17. Kirilenko, A.P.; Desell, T.; Kim, H.; Stepchenkova, S. Crowdsourcing Analysis of Twitter Data on Climate Change: Paid Workers vs. Volunteers. Sustainability 2017, 9, 2019. [CrossRef] 
18. Zheng, J.; Wu, G.; Xie, H. Impacts of Leadership on Project-Based Organizational Innovation Performance: The Mediator of Knowledge Sharing and Moderator of Social Capital. Sustainability 2017, 9, 1893. [CrossRef]

19. García-Alcaraz, J.L.; Avelar-Sosa, L.; Latorre-Biel, J.I.; Jiménez-Macías, E.; Alor-Hernández, G. Role of Human Knowledge and Communication on Operational Benefits Gained from Six Sigma. Sustainability 2017, 9, 1721. [CrossRef]

20. Ahn, S.; Kim, S. What Makes Firms Innovative? The Role of Social Capital in Corporate Innovation. Sustainability 2017, 9, 1564. [CrossRef]

21. Lytras, M.D.; Raghavan, V.; Damiani, E. Big data and data analytics research: From metaphors to value space for collective wisdom in human decision making and smart machines. Int. J. Semantic Web Inf. Syst. 2017, 13, 1-10. [CrossRef]

22. Lytras, M.D.; Mathkour, H.I.; Abdalla, H.; Al-Halabi, W.; Yanez-Marquez, C.; Siqueira, S.W.M. Enabling technologies and business infrastructures for next generation social media: Big data, cloud computing, internet of things and virtual reality. J. Univ. Comput. Sci. 2015, 21, 1379-1384.

23. Lytras, M.D.; Mathkour, H.I.; Abdalla, H.; Al-Halabi, W.; Yanez-Marquez, C.; Siqueira, S.W.M. An emerging-Social and emerging computing enabled philosophical paradigm for collaborative learning systems: Toward high effective next generation learning systems for the knowledge society. Comput. Hum. Behav. 2015, 51, 557-561. [CrossRef]

24. Lytras, M.D.; Mathkour, H.; Torres-Ruiz, M. Innovative Mobile Information Systems: Insights from Gulf Cooperation Countries and All over the World. Mob. Inf. Syst. 2016, 2016, 2439389. [CrossRef]

25. Visvizi, A.; Lytras, M.D. Rescaling and refocusing smart cities research: From mega cities to smart villages. J. Sci. Technol. Policy Mak. 2018. [CrossRef]

26. Lytras, M.D.; Visvizi, A. Who Uses Smart City Services and What to Make of It: Toward Interdisciplinary Smart Cities Research. Sustainability 2018, 10, 1998. [CrossRef]

(C) 2018 by the authors. Licensee MDPI, Basel, Switzerland. This article is an open access article distributed under the terms and conditions of the Creative Commons Attribution (CC BY) license (http:/ / creativecommons.org/licenses/by/4.0/). 